\title{
Thyroid status and its association with cognitive functioning in healthy boys at 10 years of age
}

\author{
R Pérez-Lobato', R Ramos ${ }^{1}$, J P Arrebola ${ }^{1,2}$, I Calvente ${ }^{1}, 0$ Ocón-Hernández ${ }^{3}$, \\ C Dávila-Arias', M Pérez-García ${ }^{4}$, N Olea ${ }^{1,5}$ and M F Fernández ${ }^{1,5}$ \\ ${ }^{1}$ Unit Research Support of the San Cecilio University Hospital, Instituto de Investigación Biosanitaria ibs.Granada, \\ University of Granada, 18071 Granada, Spain, ${ }^{2}$ Oncology Unit, Virgen de las Nieves University Hospital, Granada, \\ Spain, ${ }^{3}$ Department of Gynecology, Instituto de Investigación Biosanitaria de Granada, San Cecilio University \\ Hospital, University of Granada, 18071 Granada, Spain, ${ }^{4}$ Department of Clinical Psychology, University of Granada, \\ San Cecilio University Hospital, Institute of Neuroscience F, Oloriz, 18071 Granada, Spain and \\ ${ }^{5}$ CIBER en Epidemiología y Salud Pública (CIBERESP), Granada, Spain
}

Correspondence should be addressed to M F Fernández Email marieta@ugr.es

\section{Abstract}

Objective: Thyroid hormones (THs) are crucial for the correct maturation of the CNS and the neurodevelopment of the child. We aimed to investigate the association of TSH and free thyroxine $\left(\mathrm{FT}_{4}\right)$ levels with cognitive functioning in children from the INMA-Granada cohort studied during their follow-up at the age of 9-11 years.

Design: We evaluated 300 children from the original cohort, which comprised 668 eligible mother-son pairs recruited at birth from 2000 to 2002 in Granada (Spain).

Methods: $\mathrm{FT}_{4}$ and TSH concentrations were measured, and cognitive development was assessed using neuropsychological tests $(n=187)$. Children with chronic disease related to thyroid function and/or cognitive development were excluded.

Results: Median TSH and $\mathrm{FT}_{4}$ levels were $3.1 \mu \mathrm{lU} / \mathrm{ml}$ and $1.2 \mathrm{ng} / \mathrm{dl}$ respectively. In multivariable regression analyses adjusted for maternal and child characteristics, children with TSH levels in the top tertile had worse verbal comprehension and immediate and long-term recall. Children with $\mathrm{FT}_{4}$ levels in the top tertile had better attention and lower impulsivity and were at a lower risk of scoring below the 20th percentile in intelligence quotient $(\mathrm{OR}=0.24 ; 95 \% \mathrm{Cl}=0.08-0.74 ; P=0.013)$ and in abstract reasoning ability $(\mathrm{OR}=0.28 ; 95 \% \mathrm{Cl}=0.09-0.88 ; P=0.029)$.

Conclusion: Our findings indicate that circulating THs and TSH may in the top tertile have an impact on cognitive functions; thus, higher TSH slightly but significantly increased the risk of a lower score in certain neuropsychological tests.

\section{Introduction}

Thyroid hormones (THs) mediate the normal development of the brain, regulating neuronal cytoarchitecture and growth (1), myelinogenesis (2), synapse formation, and the production of neurotransmitter systems. These processes are highly sensitive to TH deficiency, and the damage caused by TH deprivation can be irreversible (2). The extent of damage depends on the magnitude and duration of the deficiency and the development period in which it occurs (3). The consequences of severe hormone deficiency include a lower intelligence quotient (IQ) and impaired neuromotor, visuospatial, memory, verbal, and attention skills $(4,5,6)$. A lesser degree of the same cognitive deficits have also been observed in cases of mild iodine deficiency $(7,8,9,10)$. Although the mechanisms by which THs affect neurological structures are not yet well known, some authors have proposed that they act predominantly on the hippocampus, prefrontal cortex, caudate nucleus, and auditory (c) 2015 European Society of Endocrinology Printed in Great Britain
Published by Bioscientifica Ltd. 
pathways, affecting memory, attention, and language functions $(4,11)$.

Few studies have addressed the association between mild-to-moderate alterations of thyroid function in children and their subsequent neuropsychological functioning $(6,10)$, and there are almost no studies investigating the neurodevelopment of healthy children with $\mathrm{TH}$ or thyrotropin (TSH) levels that only slightly differ from the 'normal' range, except for two studies from the Spanish Environment and Childhood 'Infancia y Medio Ambiente (Childhood and Environment) (INMA)' mother-child cohort study $(4,8)$.

Our working hypothesis was that neurodevelopment is an ongoing process of acquiring skills and capabilities that are not consolidated until the age of 18 years (12), and that each period during childhood is associated with the development of specific abilities. The aim of this study was to investigate the association of TSH and free thyroxine $\left(\mathrm{FT}_{4}\right)$ levels with cognitive function in children from the INMA-Granada cohort at their follow-up at $9-11$ years of age.

\section{Materials and methods}

\section{Study population}

The INMA Project is a multicentre Spanish populationbased study of a mother-child cohort designed to assess the effect of prenatal environmental exposure and diet on growth, development, and health from early fetal life until adolescence (13). From 2000 to 2002, 668 eligible motherson pairs registered at the San Cecilio University Hospital were enrolled after delivery, establishing the INMAGranada cohort, which also served to assess the prevalence of urogenital malformations (cryptorchidism and hypospadias). The inclusion and exclusion criteria were published previously (14). The follow-up of the children at the age of 9-11 years (during the period of 2010-2012) included interviews with the parents, assessment of the growth and neuropsychological status of the children, and biological sample collections (blood and urine). All families in the INMA-Granada cohort were contacted and invited to participate. This study was approved by the Ethics Committee of San Cecilio University Hospital and signed informed consent was obtained from the participants' families.

\section{Neuropsychological measures}

Evaluation of neurodevelopment was assessed using a comprehensive neuropsychological battery of tests at the
Monitoring and Early Stimulation Unit of the hospital by a neuropsychologist trained to administer the tests and interpret scores for specific neuropsychological domains.

i) General cognitive intelligence: assessed with the Kaufman Brief Intelligence Test (K-BIT) (15), in which the composite IQ is based on verbal and nonverbal scale scores.

ii) Language: evaluated with the verbal scale of the K-BIT (15), which includes two subtests: i) verbal knowledge, which measures receptive vocabulary with a task in which the child names graphically displayed objects and ii) general knowledge, and riddles, which measures expressive reasoning with a task in which children must deduce words based on a definition of the word and some of the letters it contains.

iii) Attention: assessed with the continuous performance test (CPT) (16), which measures sustained and selective attention and impulsivity with a task in which the child responds by pressing any key on the keyboard, as quickly as possible, each time the letter ' $\mathrm{A}$ ' appears in yellow ('go' condition). The main dependent variables are: hits (press any key in 'go' condition), commission errors (press any key in 'no go' condition), omission errors (no key pressed in 'go' condition), and attention index.

iv) Verbal memory: evaluated with the ComplutenseSpain Madrid verbal learning test (TAVECI) (17), which assesses different memory and learning processes, including immediate recall, short- and longterm recall, and recognition. The test involves the examiner reading a list of 15 words five times, with the child stating the words recalled after each time and then after intervals of 10 and 20 min.

v) Visual-motor coordination: assessed using part A of the trail making test (TMT) (18). The task involves connecting consecutive numbers in an alternating sequence as quickly as possible. The main dependent variable is time (s).

vi) Processing speed: measured by the sum of the results of two subtests (symbol search and coding) from the Wechsler Intelligence Scales for Children-Quarter Edition (WISC-IV) (19). The first task is to identify, as quickly as possible, whether or not figures are included in a series of figures. In the second task, the child fills in spaces under numbers with corresponding symbols following an established model. Both tasks must be completed within a maximum of $2 \mathrm{~min}$.

vii) Executive function: divided into four components: updating, inhibition, shifting, and abstract reasoning (20). 
i) Updating measurements: with two components: a) Working memory: assessed using the letternumber sequencing subtest from the WISC-IV (Spanish version), in which the child listens to and then repeats a mixed set of numbers and letters, first saying the numbers in order from the lowest to the highest and then the letters in alphabetic order (19) and b) verbal fluency: assessed using the categorical verbal fluency test (FAS), in which children are instructed to say as many names of animals as they know during $1 \mathrm{~min}$. No grammatical variations or repetitions are counted. The number of animals correctly named is the dependent variable (21).

ii) Inhibition: with two components: a) the Spanish children's version of the Stroop Color and Word Test (STROOP) (22), which measures cognition inhibition with a procedure in which the child is asked to name colored words (condition 1), read color-words printed in black ink (condition 2), and name the color of the words, which are printed in colors that conflict with their meaning, e.g. the word 'blue' appears in red ink (condition 3, inhibition). The dependent variable was the interference score, calculated from the results for the three conditions using a specific formula and b) the go/no-go task (23), which measures motor inhibition with a task in which the child responds to certain stimuli presented on the computer screen while inhibiting the response to distracter stimuli, with hit and falsealarm rates being the main dependent variables.

iii) Shifting: measured by part B of the TMT (18). The task involves connecting consecutive numbers and letters in an alternating sequence as quickly as possible, with time (s) being the main dependent variable.

iv) Abstract reasoning (matrix analogies test): measured with the non-verbal scale of the K-BIT (15), a multiple-choice test that presents stimuli in a matrix format. The child selects a picture or abstract design that best completes a visual pattern following a visual analogy. The dependent variable is the number of correct responses.

\section{Thyroid function}

Thyroid function was assessed by measuring the concentration of $\mathrm{TSH}$ and $\mathrm{FT}_{4}$ in serum samples by chemiluminescence assay (Eclecsys System, Roche Diagnostics). The limit of detection (LD) was $0.005 \mu \mathrm{IU} / \mathrm{ml}$ for $\mathrm{TSH}$ and $0.023 \mathrm{ng} / \mathrm{dl}$ for $\mathrm{FT}_{4}$. The reference range criteria proposed for children (6-11 years) by the Manual of Reference Intervals for children and Adults - http://www. katrangilab.org/UploadFolder/Files/Thyroid\%20Reference \%20data\%20Roche.pdf - are 0.60-4.84 $\mathrm{IIU} / \mathrm{ml}$ for $\mathrm{TSH}$ and $0.97-1.67 \mathrm{ng} / \mathrm{dl}$ for $\mathrm{FT}_{4}$. The pediatrician examined the thyroid of each child, finding no palpable gland and confirming the absence of a thyroid disorder in all cases.

\section{Covariates}

Information on parental socio-demographic characteristics, smoking during pregnancy, breastfeeding, and children's age, weight, and height at 9-11 years was gathered at the follow-up visit. The children's place of residence was classified as urban (city of Granada, 236000 inhabitants), sub-urban (towns of $>20000$ inhabitants in city residential belt), or rural ( $<20000$ inhabitants). We estimated the general cognitive ability of parents by assessing their verbal reasoning ability using the Similarities subtest of the Weschler Adult Intelligence-Third Edition (WAIS-III) (24).

Three hundred families (44.9\% participation rate) gave their written informed consent for this follow-up. Out of these 300 children, 18 were excluded because of the presence of chronic disease related to thyroid function and/or cognitive development, including diabetes $(n=1)$, hyperthyroidism $(n=1)$, attention deficit hyperactivity disorder (ADHD) $(n=7)$, language disorder $(n=1)$, Asperger syndrome $(n=2)$, Noonan syndrome $(n=1)$, Tourette syndrome with ADHD $(n=1)$, Charcot-Marie-Tooth syndrome with ADHD $(n=1)$, cerebral palsy $(n=1)$, Spina Bifida $(n=1)$, and brain tumor surgery $(n=1)$. Only 187 of the 300 families (62.3\%) agreed to the drawing of a blood sample from their child. Finally, data on thyroid hormone concentrations, neuropsychological tests, and covariates were available for 176 out of 300 (58.7\%) subjects.

\section{Statistical analysis}

We performed a descriptive analysis of the characteristics of children and their parents. The relationship between quantitative variables was studied using the Spearman's correlation test, and the association between quantitative and categorical variables using the Mann-Whitney $U$ test. The Kruskal-Wallis test, followed by Dunn's post hoc test, was also performed. The relationship between groups of categorical variables was explored using the $\chi^{2}$ test. 
Table 1 Characteristics of the study population (I).

\begin{tabular}{|c|c|c|}
\hline & $n$ & Mean \\
\hline \multicolumn{3}{|l|}{ Child variables } \\
\hline Age (years) & 176 & 9.8 \\
\hline BMI $\left(\mathrm{kg} / \mathrm{m}^{2}\right)$ & 176 & 18.7 \\
\hline TSH $(\mu \mathrm{IU} / \mathrm{ml})$ & 176 & 3.3 \\
\hline $\mathrm{FT}_{4}(\mathrm{ng} / \mathrm{dl})$ & 155 & 1.2 \\
\hline \multicolumn{3}{|l|}{ Maternal variables } \\
\hline Age (years) & 176 & 39.9 \\
\hline Verbal reasoning $^{a}$ & 153 & 14.8 \\
\hline \multicolumn{3}{|l|}{ Paternal variables } \\
\hline Age (years) & 175 & 42.2 \\
\hline Verbal reasoning $^{a}$ & 82 & 16.3 \\
\hline
\end{tabular}

\begin{tabular}{|c|c|c|c|}
\hline S.D. & Median & Min & Max \\
\hline 0.3 & 9.7 & 9.0 & 11.2 \\
\hline 3.5 & 18.0 & 13 & 29 \\
\hline 1.5 & 3.1 & 0.0 & 8.6 \\
\hline 0.1 & 1.2 & 1.0 & 2.8 \\
\hline 4.8 & 40.0 & 27 & 54 \\
\hline 4.9 & 14.0 & 3 & 29 \\
\hline 5.1 & 42.0 & 28 & 61 \\
\hline 4.9 & 17.0 & 2 & 32 \\
\hline
\end{tabular}

Min, minimum; Max, maximum. Parent's age at follow-up.

${ }^{a}$ Verbal reasoning, measured by similarities subtest of WAIS-III.

The association of $\mathrm{FT}_{4}$ and TSH hormone levels with neuropsychological test scores was studied using linear and logistic regression models. TSH and $\mathrm{FT}_{4}$ levels were categorized in tertiles.

Neuropsychological test results were analyzed as continuous variables based on the raw scores, because standardized scores for the Spanish child population were not available for all tests. In addition, logistic regression models were constructed to estimate the risk of obtaining scores above the 80th percentile (test: TMTA and TMTB) or below the 20th percentile (other tests) as a function of hormone levels. These percentiles were selected to enhance the detection of low or subclinical performance, as proposed by Jacobson \& Jacobson (25).

In the linear and logistic regression models, we calculated unadjusted and adjusted coefficients. Linear regression models included child's age (years), BMI $\left(\mathrm{kg} / \mathrm{m}^{2}\right)$, the mother's education (higher education/ secondary/up to primary), and smoking during pregnancy. The logistic regression models included child's age and smoking during pregnancy.

The potential influence of boys with TSH and $\mathrm{FT}_{4}$ levels outside the reference ranges $(n=23,13 \%)$ was assessed by performing a sensitivity analysis in which these children were excluded from the multivariable models.

The significance level was set at $P \leq 0.05$, following the recommendations of Rothman (26) for the evaluation of exposure-outcome relationships in the public health setting. They argue that application of the Bonferroni's correction in multiple comparisons increases the risk of missing new relationships of potential interest whose importance can be tested more reliably by replication. Data analyses were performed using SPSS v20.0 (IBM) and R statistical computing environment v3.0.0 (http://www.r-project.org/).

\section{Results}

Tables 1 and 2 show the characteristics of the study population. At the follow-up, the median age of children was 9.7 years and their median BMI was $18.0 \mathrm{~kg} / \mathrm{m}^{2}$, the median age was 40 years for mothers and 42 years for fathers, $22 \%$ of mothers and $19 \%$ of fathers had higher education, $18 \%$ of participating families lived in urban areas, $21 \%$ of mothers reported smoking during pregnancy, and $83 \%$ had breastfed the children. Median serum TSH and $\mathrm{FT}_{4}$ levels in the children were $3.1 \mu \mathrm{IU} / \mathrm{ml}$ and $1.2 \mathrm{ng} / \mathrm{dl}$ respectively. A negative correlation was observed between TSH and $\mathrm{FT}_{4}$ levels, although statistical significance was not reached $\left(r_{\mathrm{s}}=-0.113, P=0.163\right)$. The $\mathrm{FT}_{4}$

Table 2 Characteristics of the study population (II).

\begin{tabular}{|c|c|c|}
\hline & $n$ & $\%$ \\
\hline \multicolumn{3}{|l|}{ Area of residence } \\
\hline Urban & 31 & 17.6 \\
\hline Semi-urban & 114 & 64.8 \\
\hline Rural & 31 & 17.6 \\
\hline \multicolumn{3}{|l|}{ Breastfeeding } \\
\hline Yes & 146 & 83.0 \\
\hline No & 30 & 17.0 \\
\hline \multicolumn{3}{|l|}{$\begin{array}{l}\text { Smoking during } \\
\text { pregnancy }^{\mathrm{a}}\end{array}$} \\
\hline Yes & 36 & 20.5 \\
\hline No & 140 & 79.5 \\
\hline \multicolumn{3}{|l|}{ Maternal education } \\
\hline University & 38 & 21.6 \\
\hline Secondary school & 58 & 33.0 \\
\hline Up to primary & 80 & 45.5 \\
\hline \multicolumn{3}{|l|}{ Paternal education } \\
\hline University & 33 & 18.8 \\
\hline Secondary school & 58 & 33.0 \\
\hline Up to primary & 85 & 48.3 \\
\hline
\end{tabular}


value was above the upper limit of the reference range $(1.67 \mathrm{ng} / \mathrm{dl})$ in one child. The TSH value was above the upper reference range limit $(4.84 \mu \mathrm{IU} / \mathrm{ml})$ in 20 children (20/176, 11\%), and the highest value was $8.60 \mu \mathrm{IU} / \mathrm{ml}$ in one child and the TSH value was below the lower limit of the reference range $(0.60 \mu \mathrm{IU} / \mathrm{ml})$ in two children $(2 / 176$, $1.1 \%)$. None of these children had a diagnosis of thyroid disorder, despite having thyroid hormone levels outside the reference range.

No differences were found in the majority of cognitive functions and paternal characteristics between the children with and without hormone measurements (176 vs 124 subjects). However, differences were found in: shortterm recall, measured with the TAVECI test (median (P25, P75) of $11.0(10.0,13.0)$ vs $12.0(10.0,13.0), P=0.044$ respectively); father's verbal reasoning $(16.5(13.0,19.0)$ vs 14.0 (10.0, 18.0), $P=0.03$ respectively); and area of residence (urban (17.6\% vs $35.2 \%$ respectively, $P=0.001$ ) and semi-urban (64.8\% vs $45.1 \%$ respectively, $P=0.001)$ ). As reported above, $\mathrm{TSH}$ or $\mathrm{FT}_{4}$ levels were outside reference range limits in 23 children (13\%).

Bivariate analyses showed that TSH concentrations were $0.78 \mu \mathrm{IU} / \mathrm{ml}$ higher in children whose mothers smoked during pregnancy than in children of those who did not $(95 \% \mathrm{CI}=0.22,1.33 ; P=0.006)$ and that $\mathrm{FT}_{4}$ concentrations were higher in children of mothers with higher cognitive ability, with an increase of $0.007 \mathrm{ng} / \mathrm{dl}$ for each additional point on the mother's intelligence test score $(95 \% \mathrm{CI}=0.001,0.014 ; P=0.026)$. Remaining parent and child variables were not significantly associated with $\mathrm{TSH}$ or $\mathrm{FT}_{4}$ parameters.

Table 3 exhibits the raw cognitive function scores, indicating the main parameters in each test. The mean (s.D., range) raw IQ score of the children was 219.2 (22, 121-276) points and their standardized IQ was 109.0 $(12.6,52-141)$ points.

Table 3 Children's scores in neuropsychological tests.

\begin{tabular}{|c|c|}
\hline Cognitive function $^{a}$ & Test \\
\hline General cognitive & K-BIT $(I Q)^{b}$ \\
\hline Verbal expression and comprehension & $\begin{array}{l}\text { K-BIT } \\
\text { Full verbal }\end{array}$ \\
\hline Sustained attention & $\begin{array}{l}\text { CPT } \\
\text { Correct detection }^{b} \\
\text { Commission errors }^{c} \\
\text { Omissions } \\
\text { Attention Index }^{\mathrm{b}}\end{array}$ \\
\hline Verbal memory & $\begin{array}{l}\text { TAVEC } \\
\text { Immediate Recall Trial } 1^{\mathrm{b}} \\
\text { Immediate Recall Trial } 5^{\mathrm{b}} \\
\text { Learning curve }^{\mathrm{b}} \\
\text { Short-term recall }^{\mathrm{b}} \\
\text { Long-term recall }^{\mathrm{b}} \\
\text { Hits in recognition }^{\mathrm{b}}\end{array}$ \\
\hline Visual-motor coordination & TMT-A time $(s)^{c}$ \\
\hline Processing speed & $\begin{array}{l}\text { WISC-IV } \\
\text { VP }\end{array}$ \\
\hline \multicolumn{2}{|l|}{ Executive functions } \\
\hline Working memory & $\begin{array}{l}\text { WISC-IV } \\
\text { Letter-number sequencing }{ }^{b}\end{array}$ \\
\hline Verbal fluency & FAS $^{\mathrm{b}}$ \\
\hline Impulsivity/inhibition & $\begin{array}{l}\text { STROOP } \\
\text { Words }^{\mathrm{b}} \\
\text { Colors }^{\mathrm{b}} \\
\text { Words and Colors }^{\mathrm{b}} \\
\text { Interference } \\
\text { GO NO GO } \\
\text { Hit rate } \\
\text { False-alarm rate }\end{array}$ \\
\hline Shifting & TMT-B time $(s)^{c}$ \\
\hline Abstract reasoning & Matrix analogies ${ }^{b}$ \\
\hline
\end{tabular}

\begin{tabular}{c}
\hline $\boldsymbol{n}$ \\
\hline 176 \\
176 \\
\\
171 \\
171 \\
171 \\
171 \\
\\
176 \\
176 \\
176 \\
176 \\
176 \\
176 \\
175 \\
175 \\
\\
\\
176 \\
176 \\
174 \\
174 \\
174 \\
174 \\
165 \\
166 \\
175 \\
176 \\
\hline
\end{tabular}

\begin{tabular}{r}
\hline Mean \\
\hline 219.2 \\
51.5 \\
\\
63.4 \\
9.7 \\
6.5 \\
0.6 \\
\\
7.0 \\
12.0 \\
1.2 \\
11.2 \\
11.6 \\
14.5 \\
28.7 \\
\\
97.6 \\
\\
17.4 \\
17.1 \\
113.6 \\
79.0 \\
48.6 \\
2.4 \\
0.9 \\
0.0 \\
31.0 \\
\end{tabular}

\begin{tabular}{r}
\hline Media \\
\hline 220.0 \\
52.0 \\
64.0 \\
7.0 \\
6.0 \\
0.6 \\
\\
7.0 \\
12.0 \\
1.3 \\
11.0 \\
12.0 \\
15.0 \\
26.0 \\
\\
99.0 \\
\\
17.0 \\
17.0 \\
114.0 \\
79.0 \\
48.5 \\
2.2 \\
1.0 \\
0.0 \\
32.0 \\
\end{tabular}

\begin{tabular}{r}
\hline \multicolumn{1}{c}{ s.D. } \\
\hline 22.0 \\
\\
5.0 \\
\\
5.4 \\
11.9 \\
5.3 \\
0.2 \\
\\
1.7 \\
1.9 \\
0.5 \\
2.3 \\
2.4 \\
0.9 \\
10.9 \\
11.1 \\
\\
\\
2.8 \\
4.2 \\
10.3 \\
8.4 \\
7.0 \\
5.2 \\
0.0 \\
0.0 \\
35.2 \\
4.7 \\
\end{tabular}

\begin{tabular}{c}
\hline Range \\
\hline 121 to 276 \\
36 to 64 \\
43 to 70 \\
0 to 110 \\
0 to 27 \\
-0.4 to 0.9 \\
4 to 11 \\
7 to 15 \\
-1 to 3.4 \\
4 to 15 \\
4 to 15 \\
9 to 15 \\
9 to 86 \\
64 to 119
\end{tabular}

a For all tests, direct scores were used in the analysis.

${ }^{b}$ Higher score indicates better cognitive function.

'Higher score indicates worse cognitive function. 
Table 4 Association between TSH levels $(\mu \mathrm{lU} / \mathrm{ml})$ and cognitive development in children from INMA-Granada cohort $(n=176)$ $\beta$, linear regression coefficient; S.E.M. (reference group: 2 nd TSH tertile $(2.54-3.77 \mu \mathrm{IU} / \mathrm{ml})$. Significant values $(P<0.05)$ are in bold.

\begin{tabular}{|c|c|c|c|c|c|c|c|c|c|c|c|c|}
\hline \multirow[b]{4}{*}{ Cognitive functions $^{a}$} & \multicolumn{6}{|c|}{ Crude model } & \multicolumn{6}{|c|}{ Adjusted model } \\
\hline & \multicolumn{6}{|c|}{ TSH tertiles $(\mu \mathrm{IU} / \mathrm{ml})$} & \multicolumn{6}{|c|}{ TSH tertiles $(\mu \mathrm{IU} / \mathrm{ml})$} \\
\hline & \multicolumn{3}{|c|}{ 1st (0.05-2.53) } & \multicolumn{3}{|c|}{ 3rd (3.78-8.60) } & \multicolumn{3}{|c|}{ 1st (0.05-2.53) } & \multicolumn{3}{|c|}{ 3rd (3.78-8.60) } \\
\hline & $\beta$ & S.E.M. & $P$ & $\beta$ & S.E.M. & $P$ & $\beta$ & S.E.M. & $P$ & $\beta$ & S.E.M. & $P$ \\
\hline Intelligence quotient $^{\mathrm{b}}$ & -3.85 & 4.10 & 0.349 & -3.81 & 4.04 & 0.348 & -4.63 & 3.79 & 0.224 & -4.82 & 3.69 & 0.193 \\
\hline $\begin{array}{l}\text { Verbal comprehension }{ }^{\text {b }} \\
\text { Attention }\end{array}$ & -0.52 & 0.64 & 0.412 & -1.11 & 0.63 & 0.080 & -0.51 & 0.62 & 0.408 & -1.34 & 0.60 & 0.027 \\
\hline Impulsivity & 2.03 & 2.25 & 0.369 & 0.76 & 2.23 & 0.734 & 1.65 & 2.32 & 0.479 & 0.77 & 2.27 & 0.734 \\
\hline Attention index ${ }^{b}$ & -0.01 & 0.04 & 0.776 & 0.00 & 0.04 & 0.919 & -0.01 & 0.04 & 0.789 & 0.00 & 0.04 & 0.993 \\
\hline \multicolumn{13}{|l|}{ Verbal memory ${ }^{\mathrm{b}}$} \\
\hline Immediate recall ${ }^{d}$ & -0.64 & 0.36 & 0.078 & -0.74 & 0.36 & 0.042 & -0.62 & 0.36 & 0.090 & -0.80 & 0.35 & 0.026 \\
\hline Long-term recall & -0.93 & 0.44 & 0.037 & -0.82 & 0.44 & 0.065 & -1.03 & 0.45 & 0.023 & -0.96 & 0.43 & 0.030 \\
\hline Visual-motor coordination ${ }^{c}$ & -3.45 & 2.04 & 0.093 & -0.55 & 2.00 & 0.782 & -2.83 & 2.06 & 0.171 & -0.11 & 1.99 & 0.956 \\
\hline $\begin{array}{l}\text { Processing speed } \\
\text { Executive functions }\end{array}$ & 0.47 & 2.08 & 0.821 & -1.09 & 2.05 & 0.593 & -0.11 & 2.12 & 0.957 & -1.33 & 2.06 & 0.518 \\
\hline Working memory ${ }^{b}$ & 0.08 & 0.53 & 0.867 & -0.40 & 0.52 & 0.436 & -0.13 & 0.52 & 0.805 & -0.54 & 0.51 & 0.286 \\
\hline Verbal fluency ${ }^{b}$ & 0.43 & 0.79 & 0.586 & -1.22 & 0.78 & 0.119 & 0.45 & 0.80 & 0.566 & -1.30 & 0.77 & 0.097 \\
\hline \multicolumn{13}{|l|}{ Impulsivity/inhibition } \\
\hline Interference ${ }^{\mathrm{b}}$ & -0.34 & 0.99 & 0.726 & -0.14 & 0.97 & 0.886 & -0.20 & 1.02 & 0.839 & -0.17 & 0.99 & 0.863 \\
\hline Hit rate ${ }^{b}$ & 0.01 & 0.00 & 0.158 & 0.01 & 0.00 & 0.229 & 0.01 & 0.00 & 0.163 & 0.01 & 0.00 & 0.252 \\
\hline False-alarm rate ${ }^{c}$ & -0.00 & 0.01 & 0.800 & -0.01 & 0.01 & 0.316 & -0.00 & 0.01 & 0.842 & -0.01 & 0.01 & 0.278 \\
\hline Shifting $^{c}$ & -2.73 & 6.61 & 0.680 & 1.42 & 6.50 & 0.827 & -2.70 & 6.75 & 0.689 & 2.06 & 6.55 & 0.753 \\
\hline Abstract reasoning ${ }^{b}$ & -0.33 & 0.88 & 0.707 & -0.62 & 0.87 & 0.476 & -0.28 & 0.82 & 0.733 & -0.75 & 0.80 & 0.352 \\
\hline
\end{tabular}

a We show the most relevant abilities measured. For all tests, direct scores were used in the analysis.

${ }^{b} \mathrm{~A}$ higher score indicates better cognitive function.

${ }^{\mathrm{C}} \mathrm{A}$ higher score indicates worse cognitive function.

dImmediate Recall Trial 5 (TAVECl). Linear regression model adjusted for age of children, BMI $\left(\mathrm{kg} / \mathrm{m}^{2}\right)$, smoking during pregnancy, and maternal schooling.

In the model that included all of the boys, the population was categorized in tertiles of TSH levels (1st $(0.05-2.53 \mu \mathrm{IU} / \mathrm{ml}) ; 2$ 2nd $(2.54-3.77 \mu \mathrm{IU} / \mathrm{ml}) ;$ and $3 \mathrm{rd}$ $(3.78-8.60 \mu \mathrm{IU} / \mathrm{ml}))$ and $\mathrm{FT}_{4}$ levels (1st $(1.00-1.21 \mathrm{ng} / \mathrm{dl})$; 2nd (1.22-1.32 ng/dl); and 3rd (1.33-2.84 ng/dl)), taking the 2nd tertile as a reference in all cases, and the association between TSH levels and cognitive development was investigated (Supplementary Table 3, see section on supplementary data given at the end of this article). This relationship was examined by constructing multivariable linear regression models (Table 4). Unadjusted analysis showed negative associations between 3rd tertile of TSH levels and neuropsychological test scores in comparison with reference values (2nd tertile), which were statistically significant for immediate verbal recall $(P=0.04)$. Negative associations were also found between 1st tertile of TSH levels and neuropsychological test scores in comparison with reference values (2nd tertile), and the association was statistically significant for long-term verbal recall $(P=0.04)$ (Fig. 1). In the adjusted multivariable model, these associations remained significant and, additionally, the 3rd tertile of TSH levels was found to be significantly associated with long-term verbal recall
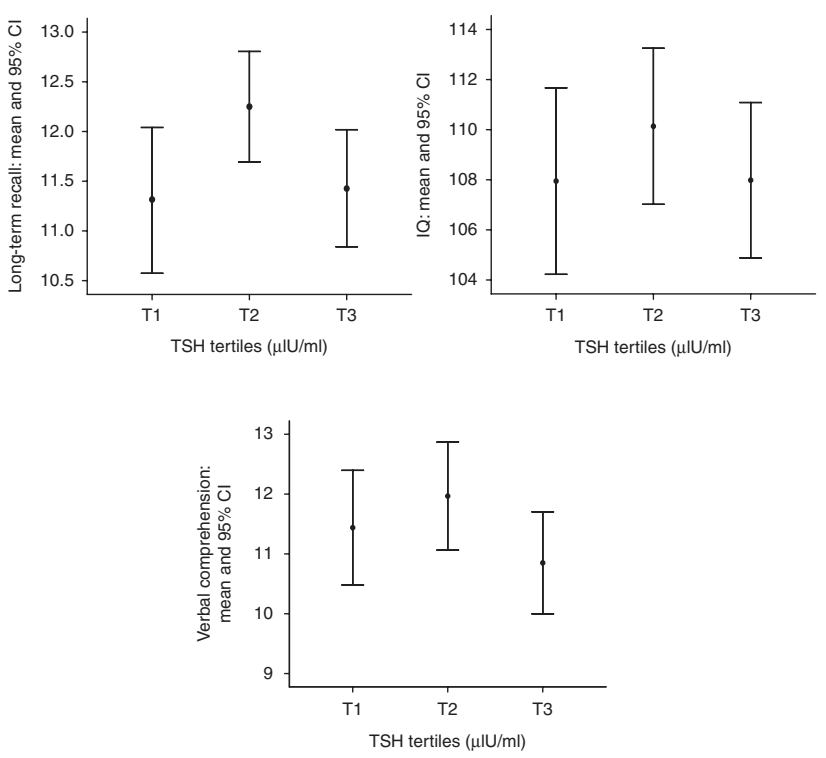

\section{Figure 1}

Association of TSH hormone levels with cognitive function using the long-term recall (raw score), verbal comprehension (raw score), and IQ (typical score). 
and with verbal comprehension (Table 4). No relevant changes in the $\beta$ coefficients were found when the analyses were performed only in the group with hormone values within reference ranges $(n=153,87 \%)$ in comparison with the model with the whole study population $(n=176)$ (Supplementary Tables 1 and 2, see section on supplementary data given at the end of this article). The longterm verbal recall ability was not significant for the third tertile in the smaller sample $(n=153)$ for the adjusted model (Supplementary Table 2).

We also explored the association between TSH levels and cognitive development by multivariable logistic regression analysis, but obtained no significant results (data not shown).

The relationship between $\mathrm{FT}_{4}$ levels and cognitive development was investigated (Supplementary Table 4, see section on supplementary data given at the end of this article). This association was examined using multivariable linear regression models (Table 5). Unadjusted analysis indicated that the IQ score, verbal expression/ comprehension, attention index, and verbal fluency abilities were positively and significantly associated with the 3rd tertile of $\mathrm{FT}_{4}$ in comparison with the reference 2 nd tertile, being a negative association for impulsivity ability (Fig. 2). When the model was adjusted for child age and BMI, maternal educational level, and smoking during pregnancy, the associations with impulsivity and attention index remained statistically significant (Table 5). No relevant changes in the regression coefficients were found when the multivariable analyses were repeated excluding the boys with $\mathrm{FT}_{4}$ values outside the reference range (data not shown).

Multivariable logistic regression models for $\mathrm{FT}_{4}$ levels and cognitive development revealed that children with $\mathrm{FT}_{4}$ levels in the 3rd tertile had a lower risk of a score $<$ P20 in the verbal expression and comprehension test $(\mathrm{OR}=$ $0.36 ; 95 \% \mathrm{CI}=0.14,0.94 ; P=0.038$ ), and children with $\mathrm{FT}_{4}$ levels in the 3rd tertile had a lower risk of a score $>$ P80 in the motor inhibition test $(\mathrm{OR}=0.32 ; 95 \% \mathrm{CI}=0.11,0.92$; $P=0.036)$ vs those with levels in the 2 nd tertile. After adjusting for child age and smoking during pregnancy, children with $\mathrm{FT}_{4}$ levels in the 3rd tertile had a lower risk of a score $<\mathrm{P} 20$ in IQ $(\mathrm{OR}=0.24 ; 95 \% \mathrm{CI}=0.08,0.74$; $P=0.013)$ and in the abstract reasoning ability $(\mathrm{OR}=0.28$;

Table 5 Association between $\mathrm{FT}_{4}$ levels $(\mathrm{ng} / \mathrm{dl}$ ) and cognitive development in children from INMA-Granada cohort ( $n=176)$. $\beta$, linear regression coefficient; s.E.M. (reference group: $2 \mathrm{nd} \mathrm{FT}_{4}$ tertile (1.22-1.32 $\mathrm{ng} / \mathrm{dl}$ ). Linear regression model adjusted for age of children, BMI $\left(\mathrm{kg} / \mathrm{m}^{2}\right)$, maternal schooling, and smoking during pregnancy. Significant values $(P<0.05)$ are in bold.

\begin{tabular}{|c|c|c|c|c|c|c|c|c|c|c|c|c|}
\hline \multirow[b]{4}{*}{ Cognitive functions $^{a}$} & \multicolumn{6}{|c|}{ Crude model } & \multicolumn{6}{|c|}{ Adjusted model } \\
\hline & \multicolumn{6}{|c|}{$\mathrm{FT}_{4}$ tertiles $(\mathrm{ng} / \mathrm{dl})$} & \multicolumn{6}{|c|}{$\mathrm{FT}_{4}$ tertiles $(\mathrm{ng} / \mathrm{dl})$} \\
\hline & \multicolumn{3}{|c|}{ 1st $(1.00-1.21)$} & \multicolumn{3}{|c|}{ 3rd (1.33-2.84) } & \multicolumn{3}{|c|}{ 1st $(1.00-1.21)$} & \multicolumn{3}{|c|}{ 3rd (1.33-2.84) } \\
\hline & $\beta$ & S.E.M. & $P$ & $\beta$ & S.E.M. & $P$ & $\beta$ & S.E.M. & $P$ & $\beta$ & S.E.M. & $P$ \\
\hline Intelligence quotient (IQ) ${ }^{\mathrm{b}}$ & 7.76 & 4.44 & 0.083 & 9.12 & 4.37 & 0.039 & 5.15 & 4.07 & 0.208 & 6.06 & 4.09 & 0.141 \\
\hline $\begin{array}{l}\text { Verbal expression and } \\
\text { comprehension }^{\mathrm{b}}\end{array}$ & 1.52 & 1.01 & 0.136 & 2.26 & 1.00 & 0.026 & 0.87 & 0.97 & 0.374 & 1.46 & 0.98 & 0.140 \\
\hline \multicolumn{13}{|l|}{ Attention } \\
\hline Impulsivityc & -4.16 & 2.47 & 0.094 & -5.78 & 2.46 & 0.020 & -3.75 & 2.54 & 0.142 & -5.38 & 2.58 & 0.039 \\
\hline Attention Index ${ }^{b}$ & 0.07 & 0.04 & 0.100 & 0.121 & 0.04 & 0.012 & 0.07 & 0.04 & 0.135 & 0.10 & 0.05 & 0.037 \\
\hline \multicolumn{13}{|l|}{ Verbal memory } \\
\hline Short Term Recall & -0.21 & 0.47 & 0.657 & 0.26 & 0.46 & 0.579 & -0.31 & 0.47 & 0.512 & 0.34 & 0.47 & 0.474 \\
\hline Long Term Recall & -0.35 & 0.49 & 0.481 & -0.07 & 0.48 & 0.886 & -0.45 & 0.49 & 0.366 & -0.10 & 0.50 & 0.835 \\
\hline Visual-motor coordination ${ }^{c}$ & 1.76 & 2.22 & 0.429 & 0.15 & 2.19 & 0.946 & 2.30 & 2.20 & 0.298 & 1.00 & 2.23 & 0.653 \\
\hline Processing speed ${ }^{\mathrm{b}}$ & -0.90 & 2.26 & 0.691 & -1.15 & 2.24 & 0.608 & -1.25 & 2.30 & 0.587 & -2.03 & 2.32 & 0.382 \\
\hline \multicolumn{13}{|l|}{ Executive functions } \\
\hline Working memory ${ }^{\mathrm{b}}$ & 0.41 & 0.58 & 0.482 & -0.09 & 0.57 & 0.863 & 0.34 & 0.57 & 0.550 & -0.27 & 0.57 & 0.639 \\
\hline Verbal fluency ${ }^{\mathrm{b}}$ & 0.58 & 0.83 & 0.481 & 1.88 & 0.82 & 0.023 & 0.44 & 0.85 & 0.606 & 1.56 & 0.85 & 0.069 \\
\hline \multicolumn{13}{|l|}{ Impulsivity/inhibition } \\
\hline Interference ${ }^{b}$ & 1.28 & 1.05 & 0.227 & 0.89 & 1.05 & 0.396 & 1.10 & 1.08 & 0.309 & 0.73 & 1.10 & 0.505 \\
\hline Hit rate ${ }^{b}$ & 0.00 & 0.01 & 0.550 & 0.00 & 0.01 & 0.795 & 0.00 & 0.01 & 0.547 & -0.00 & 0.01 & 0.770 \\
\hline False-alarm rate ${ }^{c}$ & -0.00 & 0.01 & 0.629 & -0.01 & 0.01 & 0.350 & -0.00 & 0.01 & 0.541 & -0.01 & 0.01 & 0.318 \\
\hline Shifting $^{c}$ & -5.95 & 7.30 & 0.416 & -3.03 & 7.23 & 0.675 & -3.78 & 7.41 & 0.610 & 1.12 & 7.50 & 0.881 \\
\hline Abstract reasoning ${ }^{b}$ & 1.45 & 0.93 & 0.124 & 1.69 & 0.92 & 0.069 & 0.80 & 0.86 & 0.354 & 0.88 & 0.87 & 0.311 \\
\hline
\end{tabular}

${ }^{a}$ We show the most relevant abilities measured. For all tests, direct scores were used in the analysis.

${ }^{\mathrm{b}} \mathrm{A}$ higher score indicates better cognitive function.

'A higher score indicates worse cognitive function. 

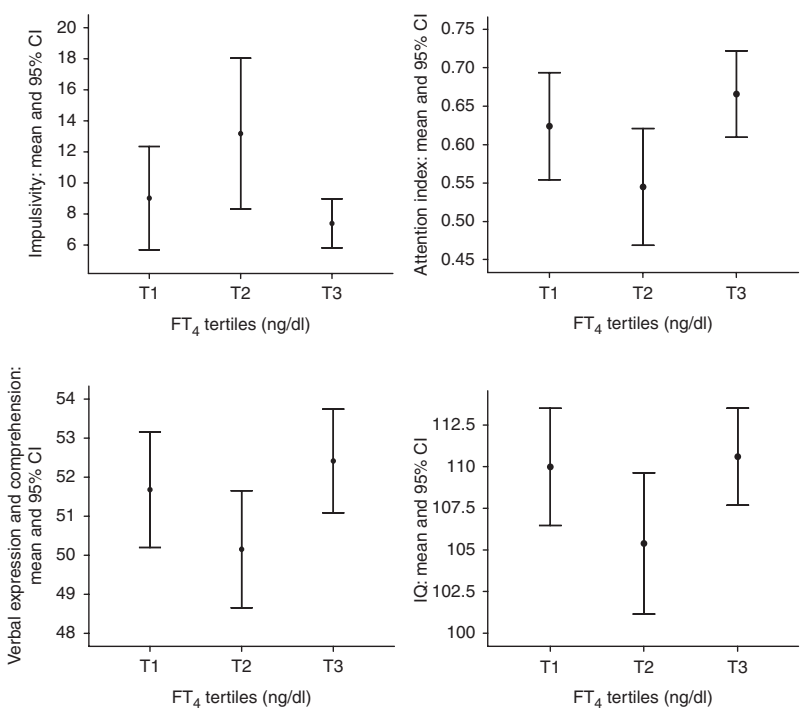

\section{Figure 2}

Association of $\mathrm{FT}_{4}$ hormone levels (in tertiles) with cognitive function using the impulsivity (raw score), attention index (raw score), verbal expression and comprehension (raw score), and IQ (typical score). A higher score indicates better cognitive function, except for impulsivity variable, in which higher score indicates worse cognitive function.

$95 \% \mathrm{CI}=0.09,0.88 ; P=0.029)$ vs those with levels in the 2nd tertile (data not shown).

\section{Discussion}

The present results in a group of healthy 10-year-old boys indicate that small deviations of TSH and $\mathrm{FT}_{4}$ levels from the accepted normal reference ranges may play a role in the modulation of cognitive functions. Thus, TSH levels around the upper reference range limit were negatively associated with verbal comprehension and immediate and long-term recall, while $\mathrm{FT}_{4}$ levels around the upper limit were positively associated with attention and negatively associated with impulsivity. In addition, boys with $\mathrm{FT}_{4}$ levels in the upper tertile had a lower risk of poor IQ scores and poor abstract reasoning ability in comparison with children with $\mathrm{FT}_{4}$ levels in the 2 nd tertile.

The differences in cognitive abilities between TSH and $\mathrm{FT}_{4}$ tertiles, although statistically significant, were small, which was expected given the non-pathological status of our study population in relation to both thyroid and cognitive functions. However, our aim was to establish the ranges of hormone (TSH and $\mathrm{FT}_{4}$ ) values associated with an increase in the risk of having fewer scores in the neuropsychological test and to identify the specific capacities affected for a closer follow-up of these boys. Moreover, we were able to identify children who tended to show lower scores in cognitive abilities and distinguish between 'normal' and 'low or subclinical' responses (25).

$\mathrm{TH}$ is known to be important in neurodevelopment, especially during periods in which the CNS is developing and maturing $(2,27,28)$. Our findings indicate that there may be a relatively narrow interval of optimal $\mathrm{TH}$ concentrations that should be identified in different populations in order to develop strategies for preventing associated adverse health effects, especially those related to neurofunctioning. It appears that the 'normal' reference ranges for $\mathrm{TH}$ levels may not be adequate to detect children at risk of low cognitive development.

Many authors have claimed that $\mathrm{TH}$ reference ranges are not the right tools to establish euthyroidism or dysthyroidism in individuals, indicating that each individual may have a unique set point for hypothalamicpituitary-thyroid axis function (29). Furthermore, the traditional methodology for determining TSH reference limits does not reflect possible differences in TSH distribution among groups according to environmental influences or their ethnic/genetic composition (30). In fact, the reference range of TSH concentrations is controversial, especially in relation to therapeutic decision making (31), with some authors recommending a reduction in the upper limit to $2.5 \mu \mathrm{IU} / \mathrm{ml}(32,33,34)$ and others associating serum levels of $5-10 \mu \mathrm{IU} / \mathrm{ml}$ with an increased risk of progression to overt hypothyroidism (35).

Our observations are consistent with previous results in the same mother-child cohort (INMA-Granada). For instance, a cross-sectional study nested in the same cohort showed lower general cognitive and quantitative capacities and executive function in 4-year-old boys with higher neonatal TSH levels (4.19-17.0 $\mu \mathrm{IU} / \mathrm{ml})$ (8). In addition, 4-year-old boys and girls in the INMA cohort with neonatal TSH concentrations in the range of 2.43-5.01 $\mu \mathrm{IU} / \mathrm{ml}$ evidenced impaired memory and verbal skills and higher attention deficit and hyperactivity/ impulsivity symptoms in comparison with those with lower TSH concentrations (4). In the same study, children with higher $\mathrm{FT}_{4}$ levels had a decreased risk of poor attention scores, in agreement with the present observations (4).

Very few studies have investigated the association between THs and neuropsychological functioning in healthy pre-pubertal children from the general population, and most of them have focused on the consequences of maternal thyroid dysfunction $(1,2,7,27,28)$. Other authors have studied specific subpopulations 
with overt thyroid diseases or in high-risk environments, including children with congenital hypothyroidism (6), neurological disorders, or thyroid hormone resistance syndrome or those living in iodine-deficient areas $(2,4,8)$.

Numerous environmental agents can produce marginal reductions of circulating THs. Although it is well documented that severe developmental hypothyroidism is profoundly detrimental to neurodevelopment, less information is available on the effects of modest $\mathrm{TH}$ deficits or on the impact of low-level $\mathrm{TH}$ disruptions induced by environmental contaminants, including endocrine-disrupting chemicals (EDCs) (36). There is increasing epidemiological evidence on the influence of environmental exposure to low doses of EDCs in some human diseases and disabilities $(36,37)$.

Our research group has previously reported that the functioning of TSH and $\mathrm{FT}_{4}$ may be affected by factors such as exposure to EDCs (38), and our results may indicate a non-monotonic response between these hormones and cognitive functions. Thus, poor child cognitive function was significantly associated with higher TSH levels but not with intermediate levels, following an inverse U-shaped curve. The relationship between higher $\mathrm{FT}_{4}$ levels and better neuropsychological scores showed a similar but inverted pattern. This U-shaped dose-response curve has also been observed for the relationship between iodine intake and thyroid disorders (39), finding an increased risk of thyroid disease in individuals with iodine intake below or above the recommended range. Non-monotonic responses and low-dose effects are remarkably common in studies of natural hormones and some EDCs (37).

The neurodevelopment of children has been associated with maternal higher education (40), the duration of breastfeeding, and various maternal lifestyle factors during pregnancy, including their diet (especially fish intake) and tobacco habit $(41,42)$. Thus, smoking during pregnancy has been related to changes in maternal and fetal thyroid function (43) and to reduced iodine concentrations in breast milk (44). In this study, TSH concentrations were higher in the offspring of mothers who smoked during pregnancy than in the children of non-smoking mothers $(P=0.006)$.

Obesity is another important factor associated with the neurodevelopment of children (45), and TSH levels are consistently found to be higher in obese children than normal-weight children (46). However, no significant relationship was found between TSH levels and BMI in this study $\left(r_{\mathrm{s}}=0.123, P=0.105\right)$. One recent review has reported that $10-23 \%$ of obese children have moderately elevated TSH levels (range of $4-10 \mu \mathrm{IU} / \mathrm{ml}$ ) and normal or slightly elevated $\mathrm{FT}_{4}$ levels. The fact that weight loss is associated with the normalization of TSH may suggest that hyperthyrotropinemia is a consequence rather than a cause of obesity (46).

Our study has several limitations. The subtle effects on cognitive abilities observed may have been mediated by other socio-cultural, economic, or genetic variables that were not controlled in this study, e.g. birth weight, dietary intake of iodine, or exposure to environmental contaminants. In addition, no data were available on other hormone biomarkers such as tri-iodothyronine $\left(\mathrm{T}_{3}\right)$, antithyroid peroxidase antibodies, and/or thyroglobulin antibody, and our population only included boys. Finally, the cross-sectional design of the study prevented evaluation of the variability of hormonal values over time, which is an important issue (32).

The strengths of our study include its novelty, given the absence of published research on these relationships in healthy children. Moreover, the sample size was relatively large, the children were followed over a 10-year interval, and data were available for multiple covariates since their birth. Finally, it contributes the results of a comprehensive neuropsychological test battery at the age of 9-11 years, a time window that allows a wide range of cognitive functions to be examined with sensitive and specific tests.

In summary, this study revealed that scores for some cognitive functions in healthy 10-year-old boys were reduced in those with higher TSH levels, and scores for some other cognitive functions were increased in those with higher $\mathrm{FT}_{4}$ levels. These findings suggest that circulating $\mathrm{TH}$ values at the limit of reference ranges may have an impact on cognitive functions, slightly but significantly increasing the risk of a lower score in certain neuropsychological tests. It is also important to determine whether these effects on cognitive functions persist over the longer term and have an adverse impact on educational performance.

\section{Supplementary data}

This is linked to the online version of the paper at http://dx.doi.org/10.1530/ EJE-14-0093.

Declaration of interest

The authors declare that there is no conflict of interest that could be perceived as prejudicing the impartiality of the research reported.

\section{Funding}

This research was supported by grants from the European Union Commission (CONTAMED FP7-ENV-2007-1-212502), the Spanish Ministry 
of Health (CIBERESP and FIS PI11/0610), and the Andalusia Regional Government, Council of Innovation, Science and Enterprise (Excellence Project P09-CTS-5488) and Council of Health (SAS PI-0675-2010). Dr J P Arrebola is currently receiving a postdoctoral fellowship from the Consejería de Igualdad, Salud y Políticas Sociales, Junta de Andalucía, Spain (RH-0092-2013).

\section{Acknowledgements}

The authors are grateful to Richard Davies for editorial assistance. The results would not have been achieved without the selfless collaboration of the study participants, pediatricians, and the Monitoring and Early Stimulation Unit (USEP) of the San Cecilio University Hospital (Granada, Spain).

\section{References}

1 Ahmed OM, El-Gareib AW, El-bakry AM, El-Tawab SM \& Ahmed RG. Thyroid hormones states and brain development interactions. International Journal of Developmental Neuroscience 200826 147-209. (doi:10.1016/j.ijdevneu.2007.09.011)

2 Muela Martínez JA, García León A, Torres Barahona R, Santiago Fernández P \& Sóriguer Escofet F. Efectos de la deficiencia de yodo sobre variables intelectuales en una población infantil. Psicothema 200820 279-284.

3 Zoeller RT \& Rovet J. Timing of thyroid hormone action in the developing brain: clinical observations and experimental findings. Journal of Neuroendocrinology 200416 809-818. (doi:10.1111/j.13652826.2004.01243.x)

4 Álvarez-Pedrerol M, Ribas-Fitó N, Torrent M, Julvez J, Ferrer C \& Sunyer J. TSH concentration within the normal range is associated with cognitive function and ADHD symptoms in healthy preschoolers. Clinical Endocrinology 200766 890-898.

5 Rovet JF. Congenital hypothyroidism: an analysis of persisting deficits and associated factors. Child Neuropsychology 20028 150-162. (doi:10.1076/chin.8.3.150.13501)

6 Rovet JF \& Hepworth S. Attention problems in adolescents with congenital hypothyroidism: a multicomponential analysis. Journal of the International Neuropsychological Society 20017 734-744. (doi:10.1017/S135561770176609X)

7 Morreale de Escobar G, Obregón MJ \& Escobar del Rey F. Is neuropsychological development related to maternal hypothyroidism or to maternal hypothyroxinemia? Journal of Clinical Endocrinology and Metabolism 200085 3975-3987.

8 Freire C, Ramos R, Amaya E, Fernández MF, Santiago P, LópezEspinosa MJ, Arrebola JP \& Olea N. Newborn TSH concentration and its association with cognitive development in healthy boys. European Journal of Endocrinology 2010163 901-909. (doi:10.1530/EJE-10-0495)

9 Santiago-Fernández P, Torres-Barahona R, Muela-Martínez JA, Rojo-Martínez G, García-Fuentes E, Garriga MJ, Leon AG \& Soriguer F. Intelligence quotient and iodine intake: a cross-sectional study in children. Journal of Clinical Endocrinology and Metabolism 200489 3851-3857.

10 Ergür AT, Taner Y, Ata E, Melek E, Bakar EE \& Sancak T. Neurocognitive functions in children and adolescents with subclinical hypothyroidism. Journal of Clinical Research in Pediatric Endocrinology 20125 21-24. (doi:10. 4274/Jcrpe.497)

11 Correia N, Mullally S, Cooke G, Kyaw Tun T, Phelan N, Feeney J, Fitzgibbon M, Boran G, O'Mara S \& Gibney J. Evidence for a specific defect in hippocampal memory in overt and subclinical hypothyroidism. Journal of Clinical Endocrinology and Metabolism 200994 3789-3797. (doi:10.1210/jc.2008-2702)
12 Mounoud P. El desarrollo cognitivo del niño: desde los descubrimientos de Piaget hasta las investigaciones actuales. Contextos Educativos 2001 4 53-77.

13 Guxens M, Ballester F, Espada M, Fernández MF, Grimalt JO, Ibarluzea J, Olea N, Rebagliato M, Tardón A, Torrent $\mathrm{M}$ et al. INMA project cohort profile: the INMA - INfancia y Medio Ambiente (Environment and Childhood) project. International Journal of Epidemiology $2012 \mathbf{4 1}$ 930-940. (doi:10.1093/ije/dyr054)

14 Fernández MF, Olmos B, Granada A, Lopez-Espinosa MJ, MolinaMolina JM, Fernández JM, Cruz M, Olea-Serrano MF \& Olea N. Human exposure to endocrine disrupting chemicals and prenatal risk factors for cryptorchidism and hypospadias. A nested case-control study. Environmental Health Perspectives 2007115 8-14. (doi:10.1289/ehp.9351)

15 Kaufman AS \& Kaufman NL. In Kaufman Brief Intelligence Test (K.BIT) Manual. Spanish Adaptation. Eds A Cordero \& I Calonge 2000 Madrid, Spain: TEA Ediciones, S.A., 1997.

16 Conners CK. In Conners' Continuous Performance Test Computer Program: User's Manual. Toronto: Multi-Health Systems, 1995.

17 Benedet MJ, Alejandre MA \& Pamos A. In TAVECI, Test de Aprendizaje Verbal España-Complutense, Infantil. Madrid, Spain: TEA Ediciones, S.A., 2001.

18 Reitan RM. Validity of the trail making test as an indicator of organic brain damage. Perceptual and Motor Skills 19588 271-276. (doi:10.2466/ pms.1958.8.3.271)

19 Wechsler D. WISC-IV. Wechsler intelligence scale for children. Nueva York: The Psychological Corporation. (adaptación española: WISC-IV. Escala de Inteligencia Wechsler para niños. Madrid: TEA Ediciones, S.A., 2007

20 Diamond A. Executive functions. Annual Review of Psychology 201364 135-168. (doi:10.1146/annurev-psych-113011-143750)

21 Benton AL \& Hamsher K. In Multilingual Aplasia Examination, $2^{a}$ Ed. Iowa City: Department of Neurology and Psychology, The University of Iowa, 1989.

22 Golden CJ. In Stroop, Test de Colores y Palabras, $4^{a}$ Ed. Madrid, Spain: TEA Ediciones, S.A., 2005.

23 Donders FC. On the speed of mental processes. Acta Psychologica 1969 30 412-431. (doi:10.1016/0001-6918(69)90065-1)

24 Wechsler D. In Escala de inteligencia de Wechsler para adultos (WAIS-III). Madrid, Spain: TEA Ediciones, S.A., 1999.

25 Jacobson JL \& Jacobson SW. Methodological issues in research on developmental exposure to neurotoxic agents. Neurotoxicology and Teratology 200527 395-406. (doi:10.1016/j.ntt.2005.01.009)

26 Rothman KJ. No adjustments are needed for multiple comparisons. Epidemiology 19901 43-46. (doi:10.1097/00001648-199001000-00010)

27 Murcia M, Rebagliato M, Iñiguez C, Lopez-Espinosa MJ, Estarlich M, Plaza B, Barona-Vilar C, Espada M, Vioque J \& Ballester F. Effect of iodine supplementation during pregnancy on infant neurodevelopment at 1 year of age. American Journal of Epidemiology 2010173 804-812. (doi:10.1093/aje/kwq424)

28 Akinci A \& Muammer KH. The effects of hypothyroidism due to iodine deficiency in neonatal brain: the changes in brain metabolites detected by magnetic resonance spectroscopy. In Comprehensive Handbook of Iodine, Nutritional, Biochemical, Pathological and Therapeutic Aspects, pp 625-634. Eds V Preedy, G Burrow, DP Smith \& R Watson, United Kingdom: Academic Press, 2009.

29 Andersen S, Pedersen KM, Henrik BN \& Laurberg P. Narrow individual variations in serum $\mathrm{T}_{4}$ and $\mathrm{T}_{3}$ in normal subjects: a clue to the understanding of subclinical thyroid disease. Journal of Clinical Endocrinology and Metabolism 200287 1068-1072. (doi:10REF35=10. 1111/j.1365-2265.1995.tb01894.x)

30 Boucai L, Hollowell JG \& Surks MI. An approach for development of age-, gender-, and ethnicity-specific thyrotropin reference limits. Thyroid 201121 5-11. (doi:10.1089/thy.2010.0092)

31 Surks MI, Goswami G \& Daniels G. The thyrotropin reference range should remain unchanged. Journal of Clinical Endocrinology and Metabolism 200590 5489-5496. (doi:10.1210/jc.2005-0170) 
32 Stephens PA. The Endocrine Society: current issues in thyroid disease management. Endocrinology News 200429 23-26.

33 Lee SL. When is the TSH normal? New criteria for diagnosis and management. Proc 12th Annual Meeting of the American Association of Clinical Endocrinologists, San Diego, CA, 2003 (thyroidtoday.com).

34 Haugen BR. When isn't the TSH normal and why? Clinical implications and causes. 12th Annual Meeting of the American Association of Clinical Endocrinologists, San Diego CA, 2003 (thyroidtoday.com).

35 Vanderpump MP, Tunbridge WM, French JM, Appelton D, Bates D, Clark F, Evans JG, Hasan DM, Rodgers H, Tunbridge F et al. The incidence of thyroid disorders in the community: a twenty-year follow-up of the Whickham Survey. Clinical Endocrinology 19953 55-68. (doi:10.1111/j.1365-2265.1995.tbOREF40=10.1016/j.infbeh. 2011.09.005)

36 Langer P, Tajtakova M, Kocan A, Drobna B, Kostalova L, Fodor G \& Klimes I. Thyroid volume, iodine intake, autoimmune thyroid disorders, inborn factors, and endocrine disruptors: twenty-year studies of multiple effects puzzle in Slovakia. Endocrine Regulations 201246 191-203. (doi:10.4149/endo_2012_04_191)

37 Vandenberg LN, Colborn T, Hayes TB, Heindel JJ, Jacobs DR, Lee DH, Shioda T, Soto AM, Saal FS, Welshons WV et al. Hormones and endocrine-disrupting chemicals: low-dose effects and nonmonotonic dose responses. Endocrine Reviews 201233 378-455. (doi:10.1210/ er.2011-1050)

38 Freire C, Lopez-Espinosa MJ, Fernández M, Molina-Molina JM, Prada R $\&$ Olea N. Prenatal exposure to organochlorine pesticides and TSH status in newborns from Southern Spain. Science of the Total Environment 2011409 3281-3287. (doi:10.1016/j.scitotenv.2011.05.037)

39 Laurberg P, Cerqueira C, Ovesen L, Rasmussen LB, Perrild H, Andersen S, Pedersen I \& Carlé A. Iodine intake as a determinant of thyroid disorders in populations. Best Practice \& Research.
Clinical Endocrinology \& Metabolism 201024 13-27. (doi:10.1016/ j.beem.2009.08.013)

40 Koutra K, Chatzi L, Roumeliotaki T, Vassilaki M, Giannakopoulou E, Batsos C, Koutis A \& Kogevinas M. Socio-demographic determinants of infant neurodevelopment at 18 months of age: Mother-Child Cohort (Rhea Study) in Crete Greece. Infant Behavior \& Development 201235 48-59. (doi:10.1016/j.infbeh.2011.09.005)

41 Mendez M, Torrent M, Julvez J, Ribas-Fitó N, Kogevinas M \& Sunyer J. Maternal fish and other seafood intakes during pregnancy and child neurodevelopment at age 4 years. Public Health Nutrition 200812 1702-1710. (doi:10.1017/S1368980008003947)

42 Julvez J, Guxens M, Carsin AE, Forns J, Mendez M, Turner MC \& Sunyer J. A cohort study on full breastfeeding and child neuropsychological development: the role of maternal social, psychological, and nutritional factors. Developmental Medicine and Child Neurology 2014 56 148-156. (doi:10.1111/dmcn.12282)

43 Shields B, Hill A, Bilous M, Knight B, Hattersley AT, Bilous RW \& Vaidya B. Cigarette smoking during pregnancy is associated with alterations in maternal and fetal thyroid function. Journal of Clinical Endocrinology and Metabolism 200994 570-574. (doi:10.1210/jc. 2008-0380)

44 Zimmermann MB, Jooste PL \& Pandav CS. Iodine deficiency disorders. Lancet 2008372 12-62. (doi:10.1016/S0140-6736(08)61005-3)

45 Liang J, Matheson BE, Kaye WH \& Boutelle KN. Neurocognitive correlates of obesity and obesity-related behaviors in children and adolescents. International Journal of Obesity 201438 494-506. (doi:10.1038/ijo.2013.142)

46 Reinehr T. Thyroid function in the nutritionally obese child and adolescent. Current Opinion in Pediatrics 201123 415-420. (doi:10.1097/MOP.0b013e328344c393)

Received 3 February 2014

Revised version received 11 September 2014

Accepted 13 November 2014 